\title{
Study for the rehabilitation of vernacular architecture with sustainable criteria.
}

\author{
I. Costa Carrapiço \& J. Neila González \\ Superior Technical School of Architecture of Madrid, Madrid, Spain
}

\begin{abstract}
This paper assesses rural vernacular heritage established in a warm temperate climate, with dry, hot summer, in São Vicente e Ventosa (SVV), Alentejo, Portugal, and takes part in a larger investigation intending to create rehabilitation guidelines, with sustainable criteria and integration of recent technologies, to improving indoor comfort, and revert the state of deterioration. To further reach this aim, this paper proposes a four phases methodology: data collection, evaluation, simulation and development; a first survey data analysis, including climate data and the adapted comfort climograph and isopleth diagram, allows an understanding of thermal comfort and main constraints in site, as well as suitable bioclimatic strategies for SVV: high thermal inertia for tempering extreme summer conditions and the considerable temperature amplitudes throughout the year, complementarily night ventilation for passive cooling, small-sized window openings and movable shading systems for solar radiation protection. An efficient behaviour in stabilizing indoor temperature swings is revealed.
\end{abstract}

\section{INTRODUCTION}

Nowadays, the development of research projects aiming to conserve built vernacular heritage has considerable impact on the global published literature. However literature linking environmental rehabilitation, focusing on the integration of innovative sustainable energy systems, with vernacular heritage is scarce. Additionally, in the last few years vernacular heritage has been reviewed concerning indoor thermal comfort, predominating published literature on the geographic areas of Mediterranean (Cardinale, 2013; Philokyprou et al. 2012), India (Priya et al. 2012) and China (Zhai et al. 2010). Very little published literature addresses this theme in portuguese vernacular dwellings. As of 1930 vernacular heritage gained bigger emphasis in the national context, resulting in the execution of a series of national inventories, covering Alentejo, to deepen habitability conditions knowledge, mainly with historical, typological and construction focus, as well as social, economic and cultural (SNA, 1961; UTL, 2013). Globally, existing assessments on vernacular dwellings in Alentejo fall back on historical, typological, construction and ethnological surveys (George et al. 2004; Veiga de oliveira et al. 1998; Moutinho, 1979; AAVV, 2013). They are also reviewed in international published literature (Fernandes, 1997).

Alentejo embodies the deterioration and abandonment issues that vernacular heritage experiences globally today, together with the disappearance of its cultural and environmental adaptation, technological and construction legacy. The traditional urban core of SVV is particularly representative of this problem, inhabited mainly by former rural workers: its vernacular dwelling typology, with a strong presence across the region and incorporating a cultural expression of it, has undergone rapid change in its exceptional preservation. Beside photographic records integrated in a few surveys (George et al. 2004; Veiga de Oliveira et al. 1998), from the comprehensive review conducted, no site-specific studies or surveys regarding its vernacular heritage were undertaken. The need in SVV for rehabilitation and revaluation of vernacular heritage, recognized both by residents and local authorities, as well as scarcity of information about it, makes it imperative to develop an intervention methodology for these settlements.

\section{RESEARCH METHODOLOGY}

This paper addresses the first part of a wider investigation, which main goal consists on proposing guidelines for rehabilitation of rural built heritage, with sustainable criteria and integration of recent technologies, aiming to improve indoor comfort, and reverting its deterioration state, while keeping the compatibility with its core values. Relying on a case study strategy, the research methodology falls back 
on a triangulation of methods, according to four major phases (Fig. 1). The first one, the data collection phase, entails both theoretical and field work: it starts with the comprehensive literature review of relevant publications, reports from international and national research projects and technical reports of surveys led by municipalities, on vernacular architecture and more specifically vernacular dwellings, vernacular architecture in Portugal and Alentejo, thermal comfort in vernacular heritage, rehabilitation with sustainable criteria and vernacular heritage, as well as geographic, climate, cultural, historical and construction data. Due to the scarcity of documentation concerning the vernacular dwellings of SVV, and toward to a profound knowledge of it, the data collection phase encompasses a fieldwork stage. It combines the acquirement of quantitative (site survey, direct in situ observations and in situ measurements) and qualitative data (questionnaire surveys and open questions); for the quantitative data, several tasks were undertaken. The first one, recognition of site by means of a global photographic survey, along with the previous literature review defines the setting of case study selection criteria within the traditional core of SVV, according to whether it is occupied or abandoned, identification of reference elements of the vernacular typology, physical condition, layout conservation. The remaining tasks were conducted upon the twenty-two case studies meeting the established criteria: geometric, morphological and construction survey; energy and environmental audit, through data loggers recording indoors and outdoors, in the two climate extreme periods throughout the year: August and January. The measurements of indoor environment entail: air temperature, relative humidity, air speed (thermal comfort), levels of natural and artificial lighting, indoor air quality (CO, CO2, COV's), and environmental noise. To assess the energy performance of the case studies, the audit includes identification of energy consumption, through access to monthly bills, energy tariff, consumption profile, contracted power, lamps and identification of electrical infrastructure and equipment. For the qualitative data, questionnaire surveys were administered to the case studies inhabitants, about thermal and visual perception, including strategies applied for heating and cooling of indoor environment (specifying the need of mechanical equipment), clothing for summer and winter period, perception of comfort in summer and winter period (from scale of 1 to 10, in which 5 is indifferent; less than 5 negative; more than 5 positive). In order contextualize the relation between traditional activities and the vernacular dwellings, open questions about socioeconomic and cultural features were administered, including training and professional occupation, number of years lived in the dwelling, number of occupants, occupancy profile of the dwelling while working and in retirement. The main goals of this first phase were to obtain a compilation of data to further analysis, characterization and deep comprehensive knowledge of the case studies performance and building technology.

The second phase, evaluation phase, aims to build a general diagnosis, setting the ground for the intervention criteria definition: it starts with the analysis of in situ survey, of both quantitative and qualitative data, in order to obtain conclusions concerning historical, material and construction systems, typomorphological, climate, environmental and energetic data. Based in the determination of needs and comfort conditions, the investigation proceeds to study the bioclimatic strategies in the vernacular dwellings of SVV, through the direct in situ observation and the corresponding Adapted Comfort Climograph and Isopleth Diagram analysis, built with the survey data assembled from the first phase; the more accurate methodology regarding the data input will be displayed in first results and discussion. After diagnosing the physical consistency of the case study settlements, intervention criteria are determined to set rules for the final development of recommendations, covering a comprehensive approach and general principles establishment, as well as specific ones regarding function y habitability, structure and material.

The third phase, simulation phase, starts with the review and selection of energy simulation softwares. The simulation process will be developed with software DesignBuilder, selected from the available softwares for suiting the investigation objectives in terms of thermal and energy analysis, with levels of comfort, internal gains and energy demands. The models of the case studies are built with information from the in situ survey data and from the literature review: site location, weather data, activity, volumetrics, occupancy profiles, construction, lighting, heating and cooling (mechanical or natural), and ventilation flow. The analysis of the obtained results focus on interpreting the energy performance of the case study (energetic gain and loss through fabric, internal loads) and indoor thermal comfort; and secondly, on contrasting the simulation results with the previous audit records, in order to validate the computer simulated models as an accurate prediction tool: by completing the previous knowledge with the simulation results, the author aims to predict the influence in performance behaviour (energetic and thermal) as a result of incorporating sustainable rehabilitation strategies.

The fourth phase, the development of the rehabilitation guidelines, divides into two work stages: the assessment of intervention measures based in the constructed computer simulated model, and the economic assessment of those measures, cost and static and dynamic amortization, leading in conclusion to the final recommendations. 


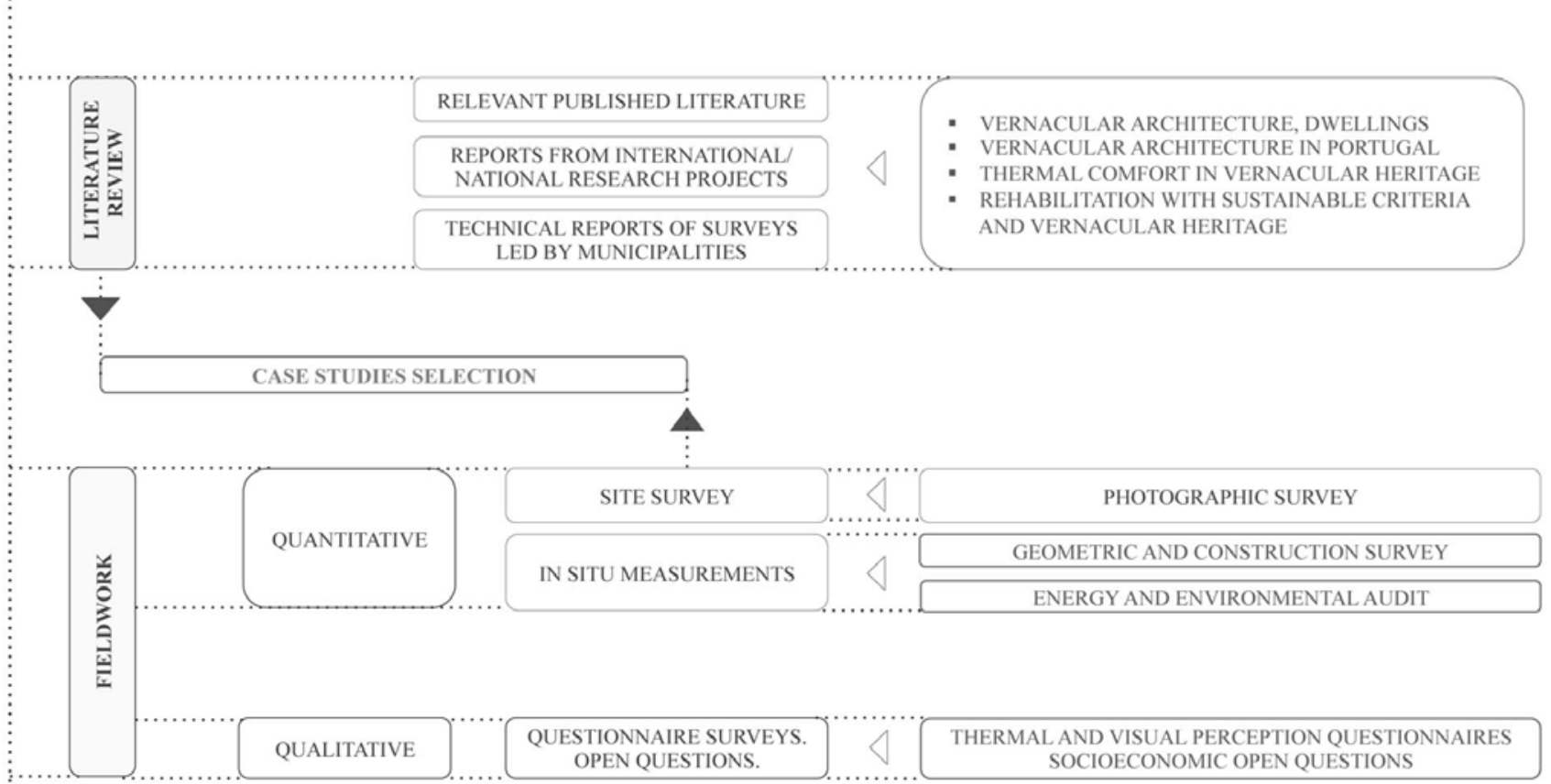

\section{PHASE II | EVALUATION}

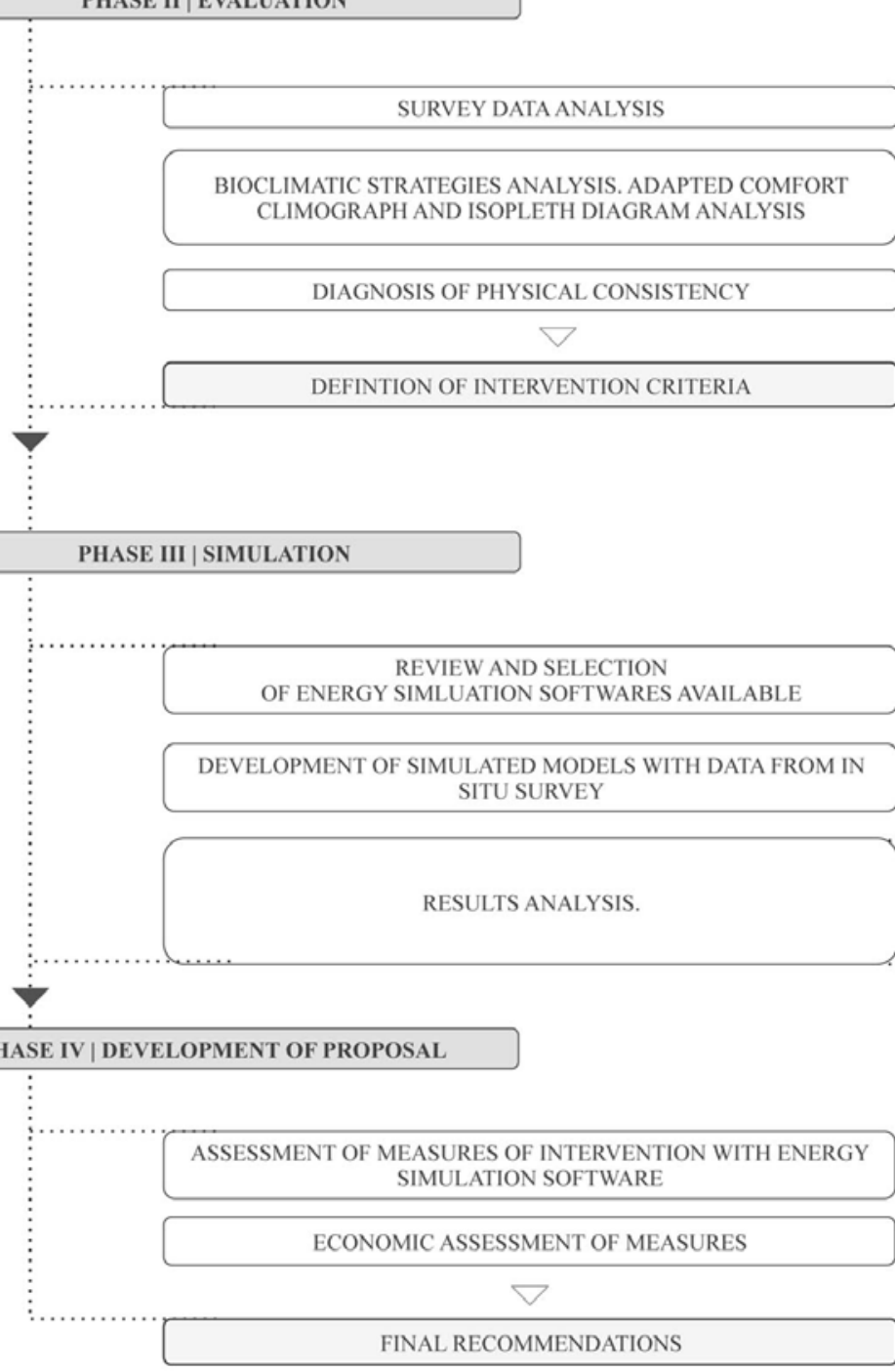

Figure 1. Research methodology scheme. 


\section{FIRST RESULTS AND DISCUSSION}

\subsection{Climate context}

According to the Köppen Climate Classification, SVV holds a temperate climate with dry or hot summer (Csa), with a particular dry period in summer and an average temperature in the hottest month above $22^{\circ} \mathrm{C}$ (AAVV, 2011). The weather data analysis does reference to data for 2011, retrieved from local meteorological office, MeteoElvas. As no data were available specifically for SVV, the data considered belong to Elvas, at a $10 \mathrm{~km}$ distance from SVV.

Air temperature. The wide warm period (June to September) records extreme maximum temperatures $\left(39^{\circ} \mathrm{C}\right.$ in July, $40^{\circ} \mathrm{C}$ in August), high averages $\left(24.7^{\circ} \mathrm{C}\right.$ in July, $25^{\circ} \mathrm{C}$ in August) and average minimum of $11^{\circ} \mathrm{C}$. The annual average value for thermal amplitudes is considerably high (around $20^{\circ} \mathrm{C}$ ), peaking between June and September $\left(25^{\circ} \mathrm{C}-28^{\circ} \mathrm{C}\right)$. In the winter period (December to March) the average temperature range varies between $8.5^{\circ} \mathrm{C}$ and $12^{\circ} \mathrm{C}$, the colder months being December and January. A tendency to little presence of transitional periods with milder temperatures, and broader extreme temperature periods, is observed.

Relative Humidity. Linked with temperature variations, daily cycles show pronounced amplitudes (variations of $88 \%$ from $6 \mathrm{~h} 00$ to $15 \mathrm{~h} 00$ ). Minimums are recorded in August and September (11\%) and daily around $15 \mathrm{~h} 00$. The average $\mathrm{RH}$ is the highest in November-February, especially during night time.

Rainfall. The annual rainfall is scanty, with an average annual accumulation of about $500 \mathrm{~mm}$, for 87 days of rain. From June to September rainfall is very scarce, both in terms of monthly accumulation (42.7 $\mathrm{mm}$ for four months) and rainy days (6 days in four months).

Wind. Direction distribution shows northwest and southwest dominant winds. With the exception of unusually high value records, average wind speed is relatively low, below the $8 \mathrm{~km} / \mathrm{h}$.

Solar Radiation. The estimation of sun hours per year is of 2820, with June and July standing out for an average of 12 sun hours per day.

This preliminary analysis of climate data leads to some considerations: first, the bioclimatic strategies employed will need to focus especially on tempering the extreme summer conditions, and secondly to meet the needs resulting from considerable temperature amplitudes.

\subsection{Bioclimatic strategies and comfort in SVV}

To study conditions of hygrothermal comfort and environmental needs in SVV, this investigation rests on its adapted comfort climograph and isopleth diagram analysis (Fig. 2): although the climograph reflects outdoor conditions, it constitutes an interesting tool to draw conclusions regarding the habitability and indoor comfort conditions, as well as which bioclimatic and design strategies best suit the needs of the site. Some considerations in regard input data: in the activity field, light work was considered, with use of hands and arms ( $80 \mathrm{~W} / \mathrm{m} 2)$, standing and sitting $(40 \mathrm{~W} / \mathrm{m} 2)$, without surface inclination or loads. The metabolic activity determined was 1.25 met $(125 \mathrm{~W})$, corresponding to the standard domestic activities (Neila et al. 2001). The resulting temperature correction by activity was $-1.51^{\circ} \mathrm{C}$. In the clothing field, according to survey questionnaires, 0.4 clo were determined for summer conditions and 1.4 clo for winter conditions (Neila et al. 2001).

By first analyzing the climograph, one observes that the comfort zone in summer months situates approximately between $25^{\circ} \mathrm{C}$ and $31^{\circ} \mathrm{C}$ of dry-bulb temperature, for $40 \%-60 \%$ of $\mathrm{RH}$. Also, the comfort zone covers part of the average day for six months. A clear separation shows between a set of warmer months (May to September), characterized by an average day partially in the comfort area, and a set of cold months (November and March), entirely outside of the comfort zone.

In the warmer months, especially between June and September, the climograph average day lines are in the dry zone, above the maximum temperature line with a RH between $23 \%-30 \%$, making clear the need for humidity and cooling strategies. Being in a dry zone, it would not be suitable to increase air speed or ventilation, but instead to apply humidification and evaporative cooling strategies, to reduce excessive temperature and ambient air dryness. In addition, the climograph shows the need for ventilation control, the most appropriate strategy being night ventilation in consequence of the large thermal amplitudes of the site, rather than permanent ventilation. Moreover, it shows the need to implement solar radiation protection strategies between May and September, as well as design strategies such the small size of window openings in the façade and external shading systems. The site's considerable daily temperature amplitude results in both cooling and heating need (through solar radiation) throughout the daily cycle of these warmer months; strategies employed should therefore be flexible to meet the needs throughout the day. In August, beside the cooling need through humidification and ventilation on the one hand, and solar radiation on the other, the humidity reaches substantial levels resulting in part of its average day in the comfort area slightly humid for health, reinforcing the need for discreet ventilation strategy. Conversely, in October and April, in addition to need for radiation in most of the day, the humidity seems to be quite low, placing in an area slightly dry for health. In relation to summer conditions in SVV, the main strategy to implement would be thermal mass construction; high thermal inertia walls acting together with night ventilation and evaporative cooling, to achieve cooling in the build- 
ing, and on the other hand, acting to supply heating need, using solar radiation.

In the cold months, the comfort zone is defined by a minimum of $23^{\circ} \mathrm{C}$ and maximum of $28.5^{\circ} \mathrm{C}$ of dry-bulb temperature, for $40 \%-60 \%$ of $\mathrm{RH}$. In comparison with summer conditions, months between November and March hold their entire average day outside of the comfort zone, hence the need for solar radiation and use of internal loads, especially in March. This may translate into the use of passive solar heating strategies, use of spontaneous internal loads, like fire, and restricting conductivity losses. Construction with strong thermal inertia properties, storing daily heat to the night period, appears once more as an appropriate strategy to meet these needs.

The Isopleth diagram displays the hourly representation of the radiation, ventilation and humidification needs to reach the comfort zone. It shows a comfort area from mid-February to early October, and very reduced comfort periods in the warmer months, essentially at night and morning periods. The larger comfort periods take place in midOctober and late February/early March. Regarding the need for evaporative cooling and ventilation, an extensive overheating situation is confirmed, between April and October, and a daily period considerably elongated, from May to mid-September (12h00-20h00) and peaking between July and September (9h00-23h00). This observation reinforces the need for tempering summer conditions and for solar radiation protection strategies. It verifies the need of both cooling and heating throughout the same day cycle, and consequently of movable external shading systems. For much of the day in June, July and August, the outdoor temperature is too elevated for proceeding to ventilation strategies, which would culminate in increased indoor temperature. Therefore, the strategy would be to profit from the night period to do so, as well as from the ceiling heights. As the need of ventilation is not continuous, the ventilation openings should have a proper locking system. There is also need for solar radiation and internal loads, as well as absence of comfort, in the most rigorous winter months (November to February) throughout all hours of the day. Thus, the need relies not only on solar radiation capture but also in retaining it, since it is needed both when there is solar incidence and when there is not. If between November and late January, the radiation need is constant, between February and November, the time difference between irradiation and heating need matches or offsets with variations between months. Providing walls with high thermal inertia would allow meeting the referred wave gap: the higher is the time gap, the more thermal inertia is required.

In synthesis, the main strategies to employ in SVV would be the provision of high thermal inertia to walls, essential to good building performance in consonance with the specific climatic and site re- quirements, in summer and winter conditions, due to its high thermal amplitudes (with especial reference to thermal amplitudes in the warmer months); acting complementarily, the night ventilation for cooling the building, with suitable locking systems; furthermore, humidification when ventilation alone is not enough, in the warmest months; finally, in terms of building design, movable shading systems and especial attention to window openings size.
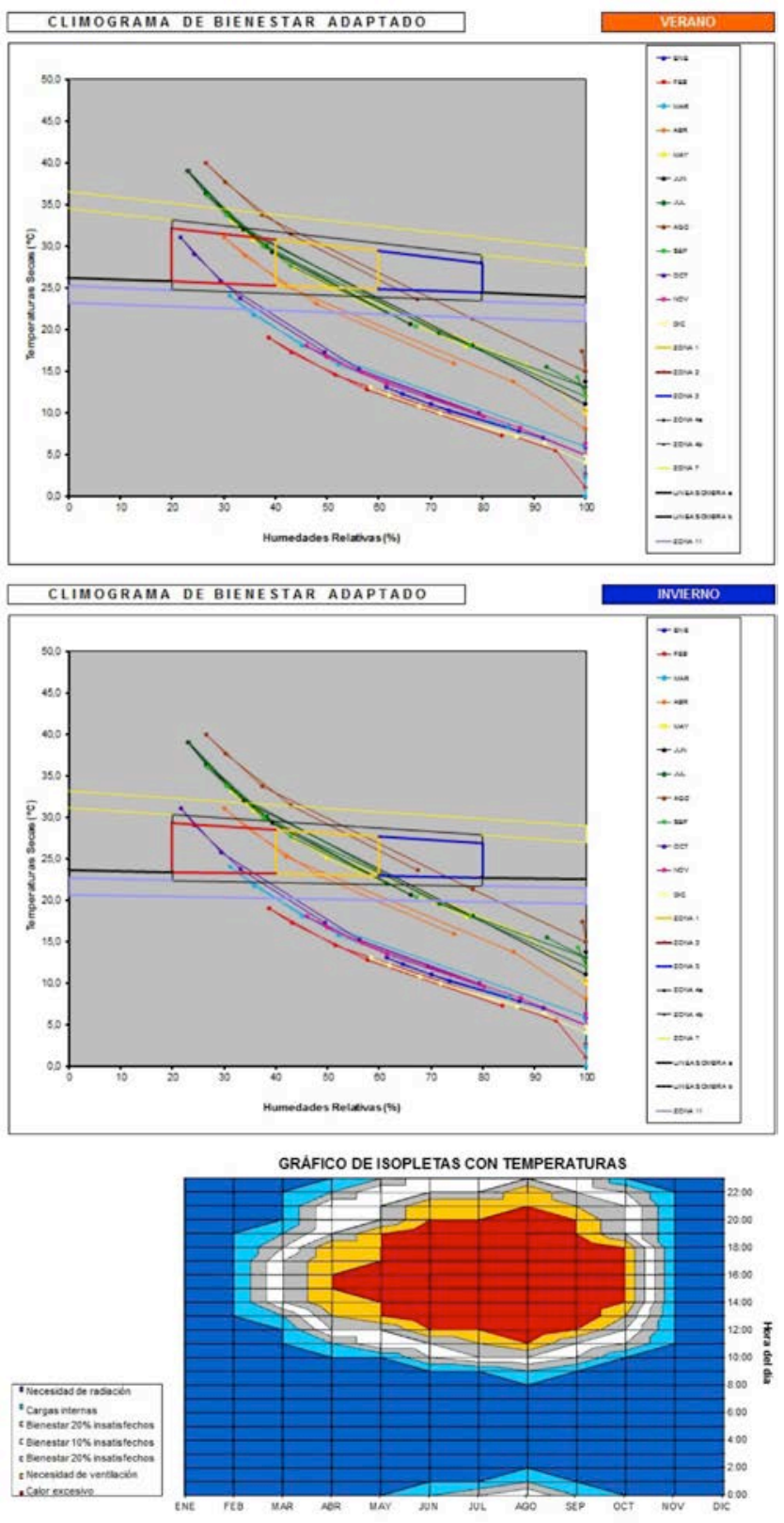

Figure 2. Adapted Comfort Climograph for summer and winter seasonal periods and Isopleth diagram.

\subsection{Considerations about the survey data}

The fieldwork results were synthetized into technical data sheet, accordingly to each task; unable to communicate in this paper the extension of it, the following paragraph focuses on the energy and environmental audit executed, process definition, example of technical data sheet systematization (Fig. 3) and commentaries on preliminary results obtained. 


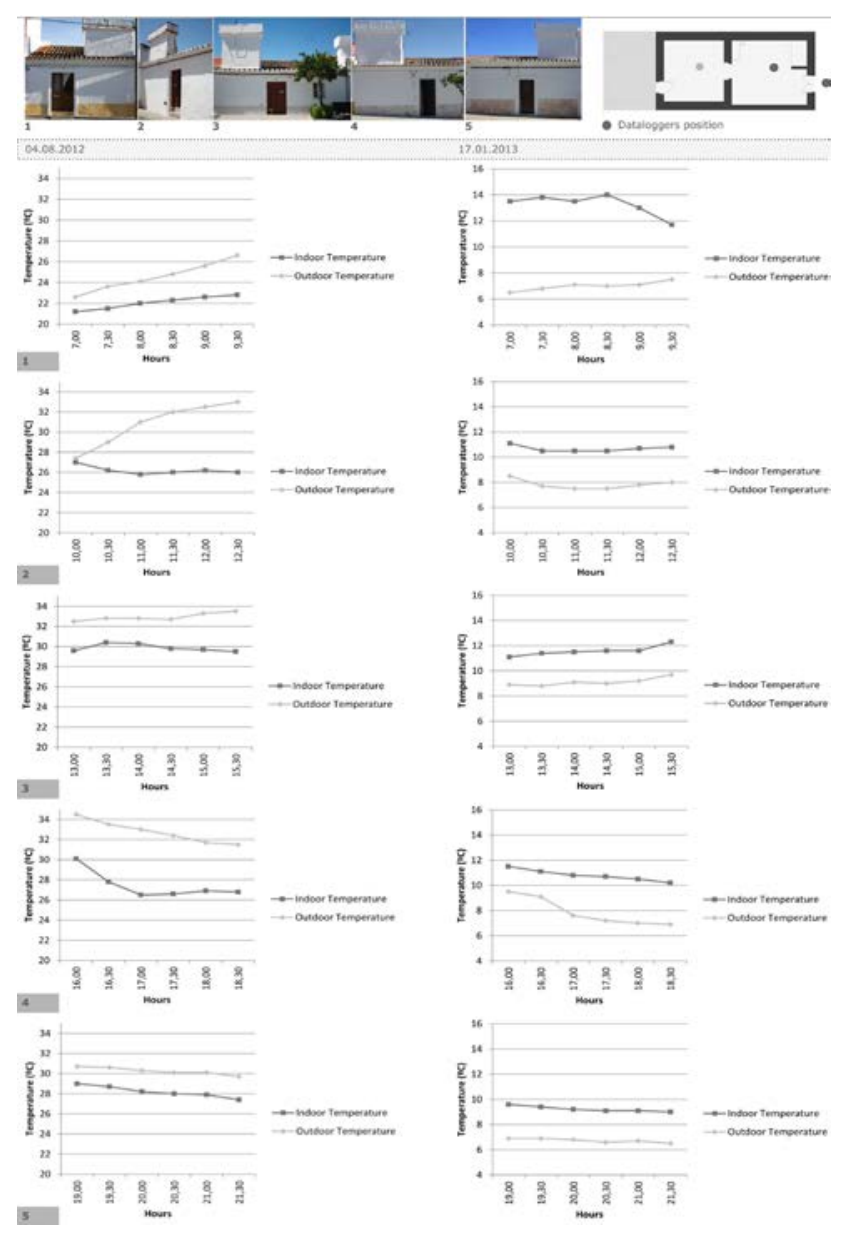

Figure 3. Example of technical data sheet, resulting from the energy and environmental audit.

The audit took place from the $1^{\text {st }}$ to $12^{\text {th }}$ of August 2012 and from the $14^{\text {th }}$ to $26^{\text {th }}$ of January 2013, from 7h00 to 21h30; however, due to logistics issues related to the inhabitants' availability, each dwelling recording time totalled $2 \mathrm{~h} 30$, with 30 minutes intervals. Figure 3 partially illustrates the systematization of the data for the 04.08.2012 and 17.01.2013, from $7 \mathrm{~h} 00$ to $21 \mathrm{~h} 30$, in the main living space of the dwelling, for five case studies.

In August, comparing the outdoor temperatures with indoor ones, one verifies that during a period of major heat (from $12 \mathrm{~h} 30$ to $17 \mathrm{~h} 00$ with a maximum $33.5^{\circ} \mathrm{C}$ ) the indoor temperature is nearly $4^{\circ} \mathrm{C}$ lower; also, one observes a considerable indoor temperature stabilization against the outdoor substantial variations, mainly from $10 \mathrm{~h} 00$ to $12 \mathrm{~h} 30$, when the temperature increases around $5.5^{\circ} \mathrm{C}$ reaching $33^{\circ} \mathrm{C}$, while indoor temperature maintains approximately $27^{\circ} \mathrm{C}$ with very little fluctuation; this demonstrates the walls' thermal inertia influence in indoor temperature stabilization. Although most of the day shows indoor temperatures averagely around comfortable temperatures, the warmest hours show the need of some extra cooling strategy by reaching a maximum of $30^{\circ} \mathrm{C}$. In January, the average temperature is quite below the comfort temperature, with a maximum $12^{\circ} \mathrm{C}$ at $15 \mathrm{~h} 30$, for $9.7^{\circ} \mathrm{C}$ outdoors. Indoor temperature fluctuation for this period reveals to be quiet low, around $3^{\circ} \mathrm{C}$, also indicating considerable temperature stabilization.

\section{CONCLUSIONS}

The four phases methodology developed revealed valuable information about adequate bioclimatic strategies for SVV: high thermal inertia for tempering extreme summer conditions and storing energy, suiting considerable temperature amplitudes throughout the year; complementarily night ventilation with locking system for passive cooling, smallsized window openings and movable shadings for solar radiation protection. Primary conclusions focusing on temperature fluctuation within the case studies reveal efficient behaviour for regulation of temperature variations, and providing comfort in summer period. However, in order to fully understand the case studies' bioclimatic, traditional passive strategies, a further study will analyse the obtained results in an integrated overview.

\section{REFERENCES}

AAVV. 2011. Atlas Climático Ibérico. Madrid: AEMET; MARM; IP.

SNA (ed.) 1961. Arquitectura Popular em Portugal. Lisboa: Sindicato Nacional dos Arquitectos.

Cardinale, N., Rospi, G. \& Stefanizzi, P. 2013. Energy and microclimatic performance of Mediterranean vernacular buildings: The Sassi district of Matera and the Trulli district of Alberobello. Building and Environment, Vol. 59: 590-598.

Fernandes, J. M. 1997. Alentejo and Algarve. In Paul Oliver (ed.) Encyclopedia of Vernacular Architecture of the World, Vol. II. Cambridge: University Press.

George, F., Gomes, A. \& Antunes, A. 2004. Arquitectura Popular em Portugal, Vol.2. Lisboa: Ordem dos Arquitectos.

MeteoElvas. 2013. Retrieved 10 January 2013, from http://www.meteoelvas.com.

Moutinho, M. 1979. A Arquitectura Popular Portuguesa. Lisboa: Editorial Estampa.

Neila González, F.J. \& Bedoya Frutos, C. 2001. Técnicas arquitectónicas y constructivas de acondicionamiento ambiental. Madrid: Editorial Munilla-Lería.

Philokyprou, M. \& Micheal, A. 2012. Evaluation of the environmental features of vernacular architecture. A case study in Cyprus. International Journal of Heritage in the Digital Era, Vol. I, Supplement I: 349-354.

Priya, R.S., Sundarraja, M.C. \& Radhakrishnan, S. 2012. Experimental study on the thermal performance of a traditional house with one-sided wind catcher during summer and winter. Energy Efficiency, 5(4): 483-496.

UTL (ed.) 2013. Inquérito à Habitação Rural. Vol.3. Lisboa: Imprensa Nacional, Casa da Moeda.

Veiga de Oliveira, E. \& Galhano, F. 1998. Arquitectura Tradicional Portuguesa. Lisboa: Publicações Dom Quixote.

Zhai, Z. \& Previtali, J. 2010. Ancient Vernacular Architecture: characteristics categorization and energy performance evaluation, Energy and Buildings, Vol. 42, Issue 3: 357-365. 